\title{
Occupational safety among dental health-care workers
}

This article was published in the following Dove Press journal:

Advances in Medical Education and Practice

7 October 2010

Number of times this article has been viewed

\section{Shigehiro Shimoji \\ Kohji Ishihama ${ }^{1,2}$ \\ Hidefumi Yamada' \\ Masaki Okayama' \\ Kouichi Yasuda ${ }^{1,3}$ \\ Tohru Shibutani $i^{3,4}$ \\ Tadashi Ogasawara ${ }^{2,5}$ \\ Hiroo Miyazawa ${ }^{2,3}$ \\ Kiyofumi Furusawa'}

'Department of Oral and Maxillofacial Surgery, Matsumoto Dental University, Shiojiri, Japan; ${ }^{2}$ Infection Control

Team, ${ }^{3}$ Risk Management Working Team, Matsumoto Dental University Hospital, Shiojiri, Japan; ${ }^{4}$ Department of Dental Anesthesiology,

${ }^{5}$ Department of Special Care Dentistry, Matsumoto Dental University, Shiojiri, Japan
Correspondence: Kohji Ishihama Oral and Maxillofacial Surgery, Matsumoto Dental University, I 780 Hirooka-Gobara, Shiojiri 399-078I, Nagano, Japan

Tel +8I 2635 I 2076

Fax +8I 263 5I 2076

Email kohji_ishi@hotmail.com
Abstract: Compared to other health-care workers, dental health-care workers come in close contact with patients and use a variety of sharp and high-speed rotating instruments. It is important to understand the characteristics of the occupational accidents that occur. We reviewed incident reports from April 1, 2005, to March 31, 2010, at Matsumoto Dental University Hospital. In addition, questionnaires dealing with identification of occupational safety issues, especially splash exposures, were conducted for dentists, dental hygienists, and nurses. Thirty-two occupational injuries were reported during the study period, including 23 sharp instrument injuries (71.9\%), 6 splash exposures (18.8\%), and 3 others. Of the six splash exposures, only two cases involved potential contamination with blood or other potentially infectious patient material. Of the 66 workers who experienced sharps injuries, 20 workers $(30.3 \%, 20 / 66)$ reported them to the hospital work safety team. The questionnaire revealed high incident of splash exposures and conjunctiva exposures: $87.9 \%(51 / 58)$ and $60.3 \%(35 / 58)$ in dentists and $88.6 \%(39 / 44)$ and $61.4 \%(27 / 44)$ in dental hygienists. The compliance rate for routine use of protective eyewear was $60.3 \%$ (35/58) for dentists and 34.1\% (15/44) for hygienists. Of the presented informational items included in the questionnaire, those that strongly persuaded respondents to use protective eyewear were 'splatters from the patient's mouth contain blood' $(90 \%, 99 / 110)$ and 'dental operations at our clinic are performed based only on a questionnaire without serious examinations for HBV, HCV, and HIV' $(71.8 \%, 79 / 110)$. The reason of low compliance of protective eyewear among dentists might relate to fine dental procedures. Appropriate information is important for the motive of wearing personal protective equipment, and an early educational program may have a potential to increase compliance with the use of that equipment.

Keywords: splash exposure, occupational safety, sharps injury, personal protective equipment

\section{Introduction}

The number of percutaneous injuries with sharp instruments is estimated to be 600,000-800,000 events annually among US health-care workers. ${ }^{1}$ All health-care workers who performed invasive procedures with sharp instruments are at risk for those injuries. In addition to percutaneous injuries, splash exposure to blood and serum also has a risk of transmitting blood-borne infection, ranging from $2 \%$ to $15.3 \% \%^{2-4}$ of total accidental blood exposure incidents. Surgeons and surgical assistants are frequently exposed to microbial pathogens via sharps injuries ${ }^{5}$ and splashes. ${ }^{6}$

In particular, dental health-care workers come in close contact with a patients' mouth during their treatment, as documented by the finding that dental students tended to show greater rates of tuberculosis infection than medical students. ${ }^{7}$ Additionally, high-speed rotating instruments, which produce large amounts of contaminated splatters 
and aerosols, ${ }^{6,8-10}$ are frequently used in dental procedures. Therefore, dental health-care workers face a significant risk of splash exposure and occupational infection via mucous and conjunctival membranes. However, only $15 \%$ are recognized by the surgeon intraoperatively, as most blood splashes are less than $0.6 \mathrm{~mm}$ in diameter. ${ }^{11}$

Thus, the present study of occupational incidents, especially with sharp injury and splash exposure in a dental hospital, was conducted by reviewing incident reports, and their prevalence and frequency were determined in our hospital. Furthermore, to investigate the concern regarding splash exposures during dental procedures, a questionnaire survey was conducted.

\section{Materials and methods}

This investigation was designed as a retrospective study and conducted at a single educational center, Matsumoto Dental University Hospital, Nagano, Japan. The medical workers consisted of 188 dentists, 45 dental hygienists, and 23 nurses at the hospital. An average total of 100,000 outpatients visited the hospital annually, and approximately 400 outpatients were cared per day. When an adverse event occurred, an incident report was systematically submitted from the person concerned to the Risk Management Work Team immediately after the event.

In order to provide information feedback, each month, the Risk Management Work Team of our hospital provided a written summary of incident reports to all staff regarding the place of occurrence and suggestions for the prevention and control of recurrence of such adverse events. We investigated the number and the content of events, the job title, the department, and clinical years of the involved staff using the summarized reports of the work team from April 1, 2005, to March 31, 2010.

In addition, questionnaires were distributed, aiming to investigate occupational safety issues, especially splash exposures. The individuals who participated in the questionnaires were 60 dentists, 45 dental hygienists, and 18 nurses.

The survey asked about the number of years of postgraduate clinical experience, the department, the sex of the respondent, the number of injuries from sharp instruments in the past, the type of instrument, the number of splash exposures, the number of conjunctival splatters, routine wearing of goggles or face shields, and reporting when events occurred.

Next, a second survey was performed regarding motivation for wearing protective eye shield equipment by years of clinical experience, department, and sex of the respondent (Table 1).
Table I Contents of occupational injuries

\begin{tabular}{ll}
\hline & Number (\%) \\
\hline Sharp instrument injury & $23(71.9)$ \\
Splash exposure & $6(18.8)$ \\
Contact exposure & $2(6.3)$ \\
Bite injury & $1(3.1)$ \\
Total & $32(100)$ \\
\hline
\end{tabular}

Note: aite injury was caused by a patient with a severe developmental disability.

\section{Results \\ Review of incident reports regarding occupational injuries}

A total of 183 documented reports were submitted during the study period. Seventy-one cases were categorized as harmful events, such as wrong medication, foreign object (dental materials) ingestion, and unexpected injury for patients, and of the 71 cases, 32 events were classified as occupational injuries. These occupational injuries occurred in 6.4 cases annually, and the incident rate was $0.0064 \%$ or one event per 15,625 outpatient visits.

The reported 32 cases regarding occupational injuries were mainly caused by sharp instrument injuries and splash exposures (Table 1). The incidents were reported commonly by dental hygienists and dentists (Table 2). Of the 14 reports from dental hygienists, 8 were about sharp instrument injuries and 5 were about splash exposures. Of the nine reports from dentists, eight were about sharps injuries and one was about a splash exposure. The three cases from nurses were needle stick injuries (two cases with a suture needle and one with a syringe needle). Of the five reports from undergraduate students, three were about sharp instrument injuries. Of the sharps injuries, five of the eight cases in dentists and seven of the eight cases in hygienists involved a sharp dental instrument, with the remainder being caused by a needle. Six splash exposures involving a dentist and hygienists were caused by liquid chemical materials for dental treatment, with five cases to the conjunctival mucosa (eye) and one cutaneous injury (face). Only one case had a potential for contamination with patient blood or other potentially infectious material (OPIM).

\section{Questionnaire regarding sharp instrument injuries}

A total of 120 responses was obtained from 58 dentists, 44 dental hygienists, and 18 nurses. The response rate was $96.7 \%$ (58/60), 97.8\% (44/45), and 100\% (18/18) from dentists, dental hygienists, and nurses, respectively.

Percutaneous occupational injuries with sharp instruments were experienced among $50 \%-60 \%$ of responded 
Table 2 Title of injured worker

\begin{tabular}{ll}
\hline & Number (\%) \\
\hline Dental hygienist & $14(43.8)$ \\
Dentist & $9(28.1)$ \\
Dental student & $5(15.6)$ \\
Nurse & $3(9.4)$ \\
CSSD staff & $1(3.1)$ \\
Total & $32(100)$ \\
\hline
\end{tabular}

Abbreviation: CSSD, central sterilization supply department.

staff, and there was no significant difference of the prevalence among job title (Table 3).

Among dentists, percutaneous injuries occurred in none $(0 \%, 0 / 11)$ in the first-year dentists, $8(57.1 \%, 8 / 14)$ in the second-year dentists, $3(42.9 \%, 3 / 7)$ in the third-year dentists, $2(50 \%, 2 / 4)$ in the fourth-year dentists, $6(66.7 \%, 6 / 9)$ in the fifth- to ninth-year dentists, and $10(76.9 \%, 10 / 13)$ in the tenthyear or later dentists. Among dental hygienists, percutaneous injuries occurred in four $(50 \%, 4 / 8)$ in the first-year dental hygienists, three $(50 \%, 3 / 6)$ in the second-year dental hygienists, three $(50 \%, 3 / 6)$ in the third-year dental hygienists, four $(50 \%, 4 / 8)$ in the fourth-year dental hygienists, five $(62.5 \%$, $5 / 8)$ in the fifth- to ninth-year dental hygienists, and seven $(87.5 \%, 7 / 8)$ in the tenth-year or later dental hygienists.

Of the 29 dentists who had experienced sharps injuries, only 3 dentists $(10.3 \%, 3 / 29)$ had reported their injuries to the work safety team in the hospital (because of incomplete answers, one dentist was excluded). Of the 26 dental hygienists with sharps injuries, $10(38.5 \%, 10 / 26)$ had reported them. Of the 11 nurses with sharps injuries, 7 nurses $(63.6 \%, 7 / 11)$ had reported them.

The number of sharps injuries among dentists accounted for 96 cases, and the kinds of instrument that caused injury included 26 cases of a syringe needle, 12 of a suture needle, 18 of a stainless wire (Figure 1A), 22 of a bur (Figure 1B), 11 of a file (Figure 1C), and 7 of a scalar tip (Figure 1D). Sharps injuries among dental hygienists accounted for 81 cases, including 23 cases of a file, 18 cases of a bur, 16 cases of a scalar tip, 10 cases of an explorer (Figure 1E), 6 cases of a syringe needle, 4 cases of a suture needle, 2 cases of a scalpel, and 2 cases of other sharps (a spatula and a stainless

Table 3 Prevalence of occupational injury

\begin{tabular}{lll}
\hline & Sharp injury & Splash exposure \\
\hline Dentist & $51.7 \%(30 / 58)$ & $88.0 \%(51 / 58)$ \\
Dental hygienist & $59.1 \%(26 / 44)$ & $88.6 \%(39 / 44)$ \\
Nurse & $61.1 \%(11 / 18)$ & $42.9 \%(6 / 14)$ \\
$\chi^{2}$ test & n.s. & $P<0.01$ \\
\hline
\end{tabular}

Abbreviations: n.s., not significant; $P$, probability value. mole). Sharps injuries among nurses accounted for 17 cases or more, including 9 cases of a syringe needle, 4 cases of a suture needle, 2 cases of a stainless wire, and 2 cases of dental forceps (Figure 1F).

\section{Questionnaire regarding splash exposures}

Of the 58 dentists, $35(60.3 \%, 35 / 58)$ routinely wore goggles or protective eyewear, including their own glasses. Of the 44 dental hygienists, $15(34.1 \%, 15 / 44)$ routinely used protective eyewear. Of the 14 nurses, $4(28.6 \%, 4 / 14)$ wore protective eye equipment.

Splash exposures were more frequently $(88.0 \%$ and $88.6 \%$ ) experienced among responded staff of dentists and dental hygienists than nurses, and there was significant difference of the prevalence among job title (Table 3 ). Splash exposures occurred in 51 dentists $(88.0 \%, 51 / 58), 39$ dental hygienists $(88.6 \%, 39 / 44)$, and 6 nurses $(42.9 \%, 6 / 14)$ (Table 3), and conjunctiva exposures occurred in 35 dentists (60.3\%, 35/58), 27 dental hygienists (61.4\%, 27/44), and 2 nurses $(14.3 \%, 2 / 14)$.

Reporting to the Risk Management Work Team in the hospital regarding splash exposure incidents was recognized in 9 dentists $(15.5 \%, 9 / 58), 12$ hygienists $(27.3 \%$, $12 / 44)$, and 6 nurses $(37.5 \%, 6 / 16)$. The motive for using appropriate personal protective equipment was obtained in 52 dentists $(94.5 \%, 52 / 55), 43$ dental hygienists $(97.7 \%$, $43 / 44)$, and 15 nurses $(93.8 \%, 15 / 16)$ after they were provided with the information on the high incidence, approximately $90 \%$, of blood-contaminated splatters during dental surgery. ${ }^{6}$

\section{Second questionnaire regarding protective eyewear}

Three months after the first questionnaire, an additional questionnaire survey was performed regarding compliance with protective eyewear and the motivation for it.

There was a total of 110 respondents ( 71 dentists and 39 dental hygienists). Of the 70 dentists and 38 hygienists who responded, 31 dentists $(44.3 \%, 31 / 70)$ and 18 hygienists $(47.4 \%, 18 / 38)$ routinely used protective eyewear.

The information or assumptions that strongly persuaded them to use protective eyewear were \#1 $(90 \%, 99 / 110)$, \#5 (71.8\%, 79/110), \#12 (66.4\%, 73/110), and \#2 (58.2\%, $64 / 110$ ) in order (Table 4). There was a significant difference between dentists who did and did not routinely wear protective eyewear for \#5 and \#12 (Table 5). No differences were 


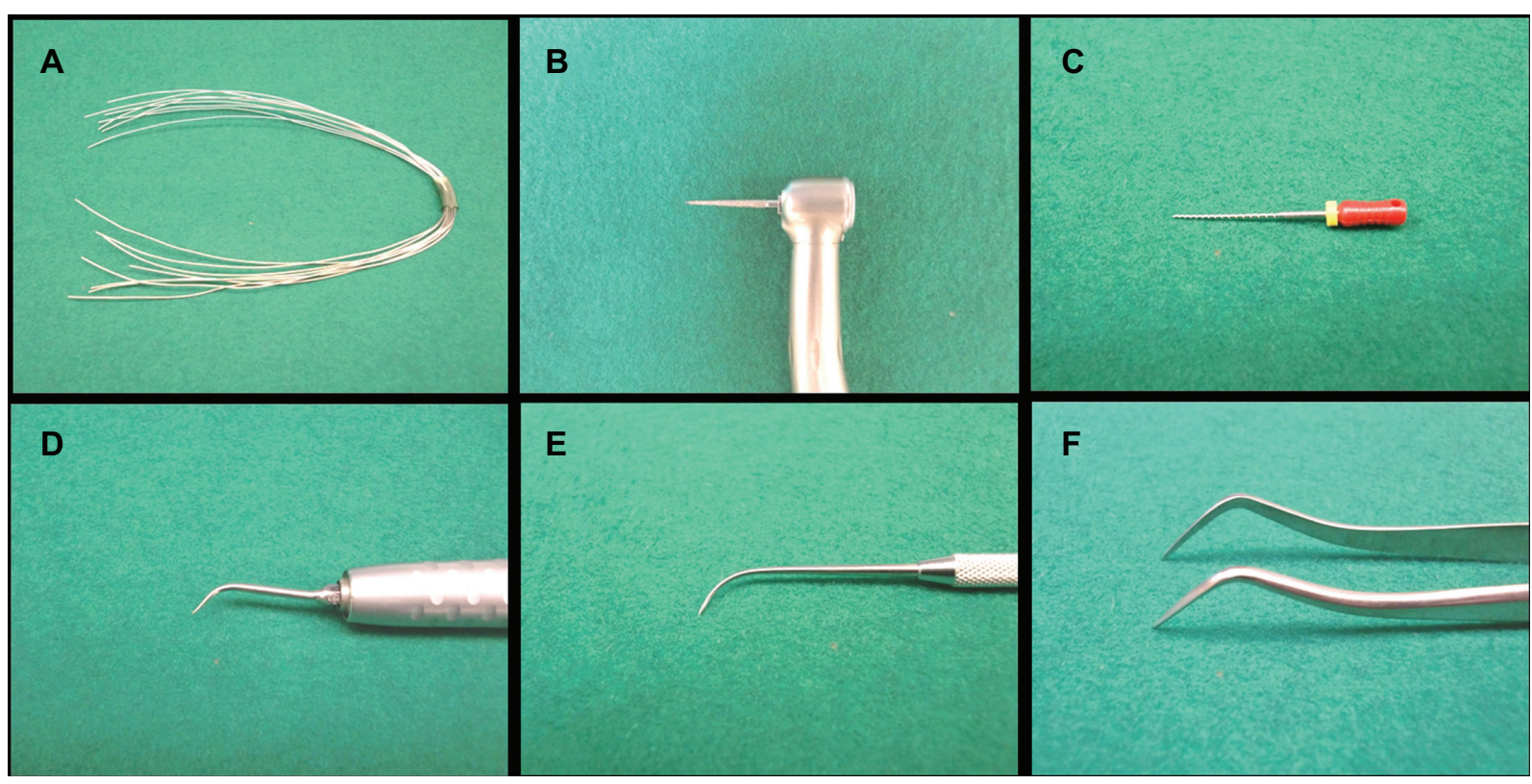

Figure I Typical sharp instruments. A) Stainless steel wires (0.4 mm in diameter). B) Dental turbine hand piece with diamond bur. C) File. D) Ultrasonic hand scalar with scalar tip. E) Explorer. F) Dental forceps.

Table 4 Questionnaire regarding motivation for wearing protective eyewear and the answers

\begin{tabular}{|c|c|c|}
\hline & Number & $\%$ \\
\hline \#I. Splatters from the patients' mouth contain blood. & 99 & 90 \\
\hline $\begin{array}{l}\text { \#2. Three splatter exposures pose an infection risk } \\
\text { equivalent to one needle stick injury. }\end{array}$ & 64 & 58.2 \\
\hline $\begin{array}{l}\text { \#3. The distance between the dentist and the patient is much } \\
\text { closer than that between the physician and the patient; } \\
\text { therefore, dentists face a greater risk for tuberculosis } \\
\text { than physicians. }\end{array}$ & 55 & 50 \\
\hline \#4. Four persons are newly infected by HIV every day in Japan. & 50 & 45.5 \\
\hline $\begin{array}{l}\text { \#5. Dental operations at our clinic are performed based only } \\
\text { on a questionnaire without serious examinations for HBV, } \\
\mathrm{HCV} \text {, and HIV. }\end{array}$ & 79 & 71.8 \\
\hline $\begin{array}{l}\text { \#6. If the hospital's reputation would be raised by using PPE, } \\
\text { I would definitely use PPE. }\end{array}$ & 17 & 15.5 \\
\hline $\begin{array}{l}\text { \#7. If my personal reputation as a good dentist would be raised } \\
\text { in the hospital by using PPE, I would definitely use PPE. }\end{array}$ & 12 & 10.9 \\
\hline $\begin{array}{l}\text { \#8. If my personal reputation as a good dentist would be raised } \\
\text { in patients' eyes by using PPE, I would definitely use PPE. }\end{array}$ & 13 & 11.8 \\
\hline $\begin{array}{l}\text { \#9. If additional reimbursement would be obtained by using } \\
\text { PPE, I would definitely use PPE. }\end{array}$ & 9 & 8.2 \\
\hline $\begin{array}{l}\# \text { I0. If the goggle or face shield would not fog up during use, } \\
\text { I would definitely use PPE. }\end{array}$ & 32 & 29.1 \\
\hline $\begin{array}{l}\text { \#I I. If the treatment time of each patient would have a } \\
\text { satisfactory length, I would definitely use PPE. }\end{array}$ & 16 & 14.5 \\
\hline $\begin{array}{l}\# \text { 12. Most splatters are not recognized by the surgeon } \\
\text { intraoperatively. }\end{array}$ & 73 & 66.4 \\
\hline $\begin{array}{l}\# 1 \text { 3. Complete information about the use of PPE is provided } \\
\text { to undergraduate students. }\end{array}$ & 29 & 26.4 \\
\hline $\begin{array}{l}\# \text { I4. There are some still unknown microbes; } 70 \text { years } \\
\text { passed before HIV was identified. }\end{array}$ & 59 & 53.6 \\
\hline
\end{tabular}

Note: Please check important information or assumptions related to your motivation for wearing protective eyewear.

Abbreviations: HIV, human immunodeficiency virus; HBV, hepatitis B virus; $\mathrm{HCV}$, hepatitis C virus; PPE, personal protective equipment. 
Table 5 Rate of agreement with the information or assumption that most strongly persuade one to use protective eyewear

\begin{tabular}{lllll}
\hline & $\begin{array}{l}\text { Thirty-one } \\
\text { dentists with } \\
\text { eyewear }\end{array}$ & $\begin{array}{l}\text { Thirty-six } \\
\text { dentists } \\
\text { without } \\
\text { eyewear }\end{array}$ & $\begin{array}{l}\text { Eighteen dental } \\
\text { hygienists with } \\
\text { eyewear }\end{array}$ & $\begin{array}{l}\text { Twenty dental } \\
\text { hygienists } \\
\text { without } \\
\text { eyewear }\end{array}$ \\
\hline$\# 1$ & $28(90.3 \%)$ & $29(80.6 \%)$ & $18(100 \%)$ & $20(100 \%)$ \\
$\# 2$ & $13(41.9 \%)$ & $21(58.3 \%)$ & $12(66.7 \%)$ & $18(90 \%)$ \\
$\# 3$ & $15(48.4 \%)$ & $14(38.9 \%)$ & $13(72.2 \%)$ & $10(50 \%)$ \\
$\# 4$ & $13(41.9 \%)$ & $16(44.4 \%)$ & $12(66.7 \%)$ & $9(45 \%)$ \\
$\# 5$ & $26(83.9 \%)$ & $18(50 \%)$ & $15(83.3 \%)$ & $16(80 \%)$ \\
$\# 6$ & $3(9.7 \%)$ & $6(16.7 \%)$ & $3(16.7 \%)$ & $3(15 \%)$ \\
$\# 7$ & $2(6.5 \%)$ & $5(13.9 \%)$ & $3(16.7 \%)$ & $2(10 \%)$ \\
$\# 8$ & $2(6.5 \%)$ & $5(13.9 \%)$ & $3(16.7 \%)$ & $3(15 \%)$ \\
$\# 9$ & $1(3.2 \%)$ & $4(11.1 \%)$ & $2(11.1 \%)$ & $2(10 \%)$ \\
$\# 10$ & $10(32.3 \%)$ & $13(36.1 \%)$ & $5(27.8 \%)$ & $4(20 \%)$ \\
$\# 11$ & $5(16.1 \%)$ & $4(11.1 \%)$ & $3(16.7 \%)$ & $4(20 \%)$ \\
$\# 12$ & $24(77.4 \%)$ & $17(47.2 \%)$ & $16(88.9 \%)$ & $13(65 \%)$ \\
$\# 13$ & $7(22.6 \%)$ & $8(22.2 \%)$ & $9(50 \%)$ & $5(25 \%)$ \\
$\# 14$ & $14(45.2 \%)$ & $20(55.6 \%)$ & $10(55.6 \%)$ & $12(60 \%)$ \\
\hline
\end{tabular}

Notes: Bold show a significant difference between dentists with and without routine protective eyewear ( $P$ value $<0.01$ and $<0.05$ in $\# 5$ and \#12, respectively, $\chi^{2}$ test).

noted between hygienists who did and did not wear protective eyewear and between dentists and hygienists.

\section{Discussion}

Reporting splash exposure incidents was not recognized by most of the workers, despite a high incidence of exposure to blood and OPIMs during dental procedures with high-speed instruments. This study demonstrated that dental health-care workers had a low level of concern regarding splash exposures to OPIMs. Saliva is recognized as an OPIM regardless of whether blood is visible, because even when blood is not visible, it can still be present in limited quantities. ${ }^{12,13}$ Even a small amount of splash exposure during dental procedures are an important issue of occupational safety. In this section, we focus on the splash exposures, comparing them with sharps injuries, which should increase compliance with protective eyewear.

\section{Review of incident reports}

Based on daily clinical experience, approximately $90 \%$ of oral surgeons have been exposed to blood-contaminated splatters during third molar surgery, ${ }^{6}$ and even scaling with an ultrasonic hand scalar produced blood-contaminated aerosols, ${ }^{8,9}$ but the occurrence of splash exposures, which accounted for $18.8 \%$ (6/32) of all reported harmful events among health-care workers, seemed low. In addition, six splash exposure incidents reported by dentists and hygienists were mainly caused by liquid chemical materials for dental treatment, and only two cases had the potential for OPIM contamination. Because even needle stick injuries, which are recognized as carrying a more concentrated infection than splash exposures, among surgeons were often not reported to an employee health service, ${ }^{5,14,15}$ the persons concerned might disregard the events. UK studies estimated that the degree of underreporting of sharps injuries might be as much as 10 -fold. ${ }^{16}$ Cases of occupational splash exposure to blood and OPIMs seemed to occur more often than reported.

\section{Questionnaire regarding sharp instrument injuries}

Percutaneous injuries among dentists and hygienists increased with years of clinical experience to approximately $90 \%$, as reported previously. ${ }^{5}$ Of all 66 workers who had experienced sharps injuries, only 20 workers $(30.3 \%, 20 / 66)$ had reported them to the workplace safety team in the hospital. Low compliance with reporting was observed in other articles, ranging from $22 \%$ to $49 \%$. $^{5,14,15}$ This underscores the need for ongoing attention to strategies to reduce such injuries in a systematic way and improve reporting systems so that appropriate medical care can be delivered. ${ }^{5}$

The instruments that caused sharps injuries differed by job title for dentists, hygienists, and nurses. Syringe needles were common instruments among dentists and nurses, while files and burs were common among dental hygienists (Figure 2). Dental hygienists in our hospital are usually involved in oral care for periodontitis patients as assistants to a dentist and in cleaning instruments (Figure 2A) and the dental chair unit (Figure 2B). Unlike dentists and nurses, they were injured during cleaning after treatment, not during treatment. The same result was reported from the UK; that is, more injuries occurred after the treatment session. ${ }^{17}$ On the other hand, among dental students in training, significantly more incidents occurred while a patient was being treated than during cleanup procedures. ${ }^{18}$ Hurrying because of multiple procedures and time pressure, as well as a feeling of being 'rushed' may result in further medical errors or occupational risks.

\section{Questionnaire regarding splash exposures}

The rates of obvious incidents of splash exposures were extremely high $-87.9 \%(51 / 58)$ in dentists and $88.6 \%(39 / 44)$ in dental hygienists - while the rate was approximately half $(42.9 \%, 6 / 14)$ in nurses. Dental procedures generally produce 

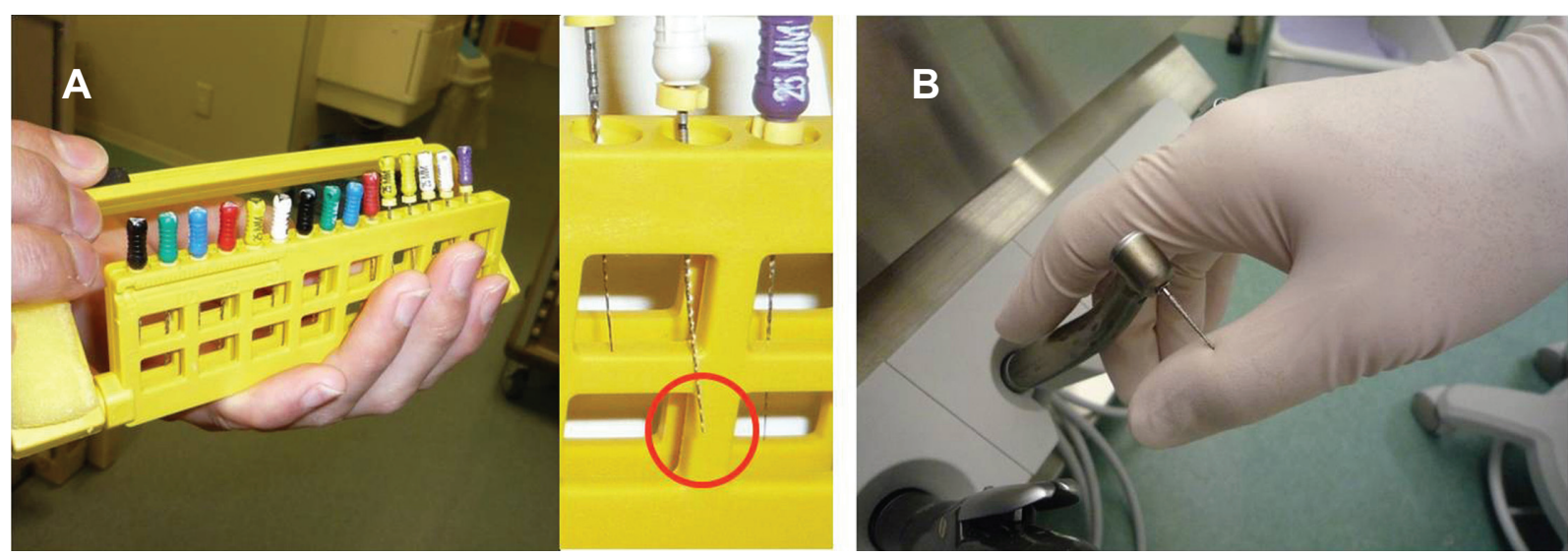

Figure 2 Examples of injured cases. A) Sharp instrument (a file) injury after treatment. The tip of a file is protruding from the instrument stand (red circle). B) Unexpected injury could occur during and after treatment. Left bur or scalar tip with hand pieces has a potential risk for injury.

splatters and aerosols, ${ }^{8}$ and protective eyewear should be routinely used by dentists and their assistants according to the University policy, which was written in conformity with CDC guideline. ${ }^{12}$ However, compliance with routine protective eyewear was low $-60 \%$ in dentists and $34 \%$ in hygienists - similar to the $44 \%$ reported previously. ${ }^{15}$ Because of the existence of imperceptible contaminated splatters and aerosols, ${ }^{10,19}$ effective educational information is needed to provide motivation.

The reasons given for not routinely using protective eyewear were, not carrying such eyewear, no time for wearing, unsatisfactory function, and low concern for precautions (data not shown). The answers regarding unacceptable function of protective eyewear among workers who did not use such eyewear routinely were, unclear view with fog and reflection. Though safety devices have been developed, product improvements are needed more, such as clear, nonfog, nonreflective shields that are convenient to carry.

In the second questionnaire, participants most frequently identified the following reasons for wearing protective eyewear: \#1 splatters from the patients' mouth contain blood, \#5 dental operations at our clinic are performed based only on a questionnaire without serious examinations for $\mathrm{HBV}, \mathrm{HCV}$, and HIV, \#12 most splatters are not recognized by the surgeon intraoperatively, and $\# 2$ three splatter exposure incidents pose an infection risk equivalent to one needle stick injury. A significant difference between dentists who did and did not routinely use protective eyewear was recognized in the responses to \#5 and \#12; the degree of recognition of the need for precaution to avoid eye injuries and conjunctiva exposure may be a factor. Although the number of people infected with HIV is increasing in Japan and is a medico-social problem, the awareness of the potential risk for HIV infection is still low. Quite different results may be obtained if the questionnaire were done at the medical institution where many patients infected with HIV visit. The protective eyewear seemed to be used depending on the risk for infectious pathogens and the equipment quality. Appropriate information from an early educational program appears to play an essential role in increasing compliance with the use of personal protective equipment. To confirm this, further investigations on the effect of interventions, such as reorganization of curriculum for occupational safety especially splash exposures, and educational program for wearing goggle or face shield are required.

\section{Disclosure}

The authors report no conflicts of interest in this work.

\section{References}

1. NIOSH. Alert: Preventing Needlestick Injuries in Health Care Settings. Washington (DC): National Institute for Occupational Safety and Health; 1999 (Publication no. 2000-108).

2. Younai FS, Murphy DC, Kotelchuck D. Occupational exposures to blood in a dental teaching environment: results of a ten-year surveillance study. J Dent Educ. 2001;65(5):436-448.

3. Tarantola A, Koumaré A, Rachline A, et al. A descriptive. Retrospective study of 567 accidental blood exposures in healthcare workers in three West African countries. J Hosp Infect. 2005;60(3):276-282.

4. Machado-Carvalhais HP, Ramos-Jorge ML, Auad SM, Martins LH, Paiva SM, Pordeus IA. Occupational exposure to potentially infectious biological material in a dental teaching environment. J Dent Educ. 2008;72(10):1201-1208.

5. Makary MA, Al-Atter A, Holzmueller CG, et al. Needlestick injuries among surgeons in training. $N$ Engl J Med. 2007;356(26): 2693-2699.

6. Ishihama K, Iida S, Koizumi H, et al. High incidence of blood exposure due to imperceptible contaminated splatters during oral surgery. J Oral Maxillofac Surg. 2008;66(4):704-710.

7. Shaw BA. Tuberculosis in medical and dental students. Lancet. 1952;2:400-404.

8. Harrel SK, Molinari J. Aerosols and splatter in dentistry: a brief review of the literature and infection control implications. J Am Dent Assoc. 2004;135(4):429-437. 
9. Yamada H, Ishihama K, Yasuda K, et al. Aerial dispersal of blood-contaminated aerosols during dental procedures. Quintessence Int. In press 2010.

10. Ishihama K, Koizumi H, Wada T, et al. Evidence of aerosolised floating blood mist during oral surgery. J Hosp Infect. 2009;71(4):359-364.

11. Collins D, Rice J, Nicholson P, Barry K. Quantification of facial contamination with blood during orthopaedic procedures. J Hosp Infect. 2000;45(1):73-75.

12. CDC. Updated US public health service guidelines for the management of occupational exposures to HBV, HCV, and HIV and recommendations for postexposure prophylaxis. MMWR Recomm Rep. 2001;50:1-52.

13. US Department of Labor, Occupational Safety and Health Administration Occupational exposure to bloodborne pathogens; needlesticks and other sharps injuries; final rule. Fed Regist. 2001;66:5317-5325.

14. Nagao M, Iinuma $Y$, Igawa $J$, et al. Accidental exposures to blood and body fluid in the operation room and the issue of underreporting. Am J Infect Control. 2009;37(7):541-544.
15. Wicker S, Rabenau HF. Occupational exposures to bloodborne viruses among German dental professionals and students in a clinical setting. Int Arch Occup Environ Health. 2010;83(1):77-83.

16. Elder A, Paterson C. Sharps injuries in UK health care: a review of injury rates, viral transmission and potential efficacy of safety devices. Occup Med (Lond). 2006;56(8):566-574.

17. Stewardson DA, McHugh S, Palenik CJ, Burke FJ. Occupational exposures occurring among dental assistants in a UK dental school. Prim Dent Care. 2003;10(1):23-26.

18. Stewardson DA, Palenik CJ, McHugh ES, Burke FJ. Occupational exposures occurring in students in a UK dental school. Eur J Dent Educ. 2002;6(3):104-113.

19. Ishihama K, Sumioka S, Sakurada K, Kogo M. Floating aerial blood mists in the operating room. J Hazard Mater. 2010;181:1179-1181.
Advances in Medical Education and Practice

\section{Publish your work in this journal}

Advances in Medical Education and Practice is an international, peerreviewed, open access journal that aims to present and publish research on Medical Education covering medical, dental, nursing and allied healthcare professional education. The journal covers undergraduate education, postgraduate training and continuing medical education

\section{Dovepress}

including emerging trends and innovative models linking education, research, and healthcare services. The manuscript management system is completely online and includes a very quick and fair peer-review system. Visit http://www.dovepress.com/testimonials.php to read real quotes from published authors.

Submit your manuscript here: http://www.dovepress.com/advances-in-medical-education-and-practice-journal 